\title{
Top-of-Rail Lubricants: Potential Risks and Benefits ${ }^{\dagger}$
}

\author{
Radovan Galas *, Milan Omasta and Martin Hartl \\ Faculty of Mechanical Engineering, Brno University of Technology, Technicka 2896/2, 61669 Brno, \\ Czech Republic; Milan.Omasta@vut.cz (M.O.); Martin.Hartl@vut.cz (M.H.) \\ * Correspondence: Radovan.Galas@vut.cz; Tel.: +420-54114-3239 \\ + Presented at 2018 International Symposium on Rail Infrastructure Systems Engineering (i-RISE 2018), Brno, \\ Czech Republic, 5 June 2018.
}

Published: 17 September 2018

\begin{abstract}
Top-of-rail (TOR) lubricants represent modern approach for friction modification between wheel and rail. The main goal of this study was to investigate potential risks and benefits associated with the application of these products, especially in terms of adhesion, wear, and noise. For this purpose, both laboratory and field experiments were carried out.
\end{abstract}

Keywords: adhesion; corrugation; rail-wheel tribology; squeal noise; top-of-rail lubricant; wear

\section{Introduction}

Friction between wheel and rail represents one of the key factor influencing efficiency and safety of rail transportation. Two traditional methods of friction management, namely sending and wheelflange lubrication, are widely used all over the world. Although both these methods are effective and proven by many decades, there are still problems which persist such as e.g., squeal noise or corrugation. To overcome these undesired phenomena, TOR lubrication is often employed. TOR products can be generally divided into two sub-classes: TOR friction modifiers (water-based materials) and TOR lubricants (oil or grease-based materials). So far published articles have been almost exclusively focused on the performance of friction modifiers. It was revealed that these waterbased products are able to provide the intermediate level of adhesion, reduce wear, suppress corrugation formation, and reduce unpleasant squeal noise. In contrast, only little was published about potential risks and benefits of TOR lubricants. Therefore, the aim of this study was to clarify the behavior of TOR lubricants within the wheel-rail contact.

\section{Materials and Methods}

Experimental research was carried out both in laboratory and in field conditions. In the case of laboratory research, the ball-on-disc was utilized to investigate friction behavior of two commercial TOR lubricants (identified as TORL-A and TORL-B). Besides that, the effect of TOR lubricants on wear and surface damage was evaluated using 3D optical microscope and analytic balance. In the case of field tests, the impact of TORL-A on the tram braking distance and the level of noise was assessed. For this purpose, the curve section of the light rail system in Brno (The Czech Republic) was used. The rail profile and curve radius was 49E1 and $200 \mathrm{~m}$ respectively.

\section{Results}

Figure 1a shows the results of laboratory experiments [1], particularly adhesion (traction) curves for dry and lubricated conditions. Each point on adhesion curve represents the average value of the adhesion coefficient from the time test, which was conducted for various slip values. Obtained adhesion curves clearly show that both tested TOR lubricants provide the intermediate level of adhesion as well as the positive friction characteristic. This positive trend of adhesion curves 
suppresses corrugation formation which has a negative impact on noise and comfort of passengers. After completion of these measurements, wear rate and surface topography of specimens were evaluated. It was revealed that TOR lubricants are able to reduce wear rate and surface damage.

Based on the above-mentioned laboratory experiments [1], TORL-A was chosen as a suitable TOR lubricant for field trials [2] where TOR lubricant was applied using newly developed off-board system. Figure $1 \mathrm{~b}$ shows the results of braking tests [2] where the effect of applied quantity on the tram braking distance was investigated. It is evident that larger quantities (4 and $2 \mathrm{~g} / \mathrm{rail}$ ) led to the unacceptable long braking distances as a result of contact overdosing, see Figure $1 \mathrm{~b}$. Moreover, these extensions of braking distances were accompanied by wheel slides leading to the formation of flat spots. With respect to these results, the quantity of $1 \mathrm{~g} /$ rail was used for long-term experiments where the level of noise was monitored under real operating conditions. It was found that there is almost negligible effect of TOR lubricant on the level of noise (less than $1 \mathrm{dBA}$ ), however, it should be noted that the noise reduction considerably depends on the type of tram. While the significant reduction of noise was found for the newest model of trams (up to $5 \mathrm{dBA}$ ), almost no decrease of noise was observed for older type of trams.
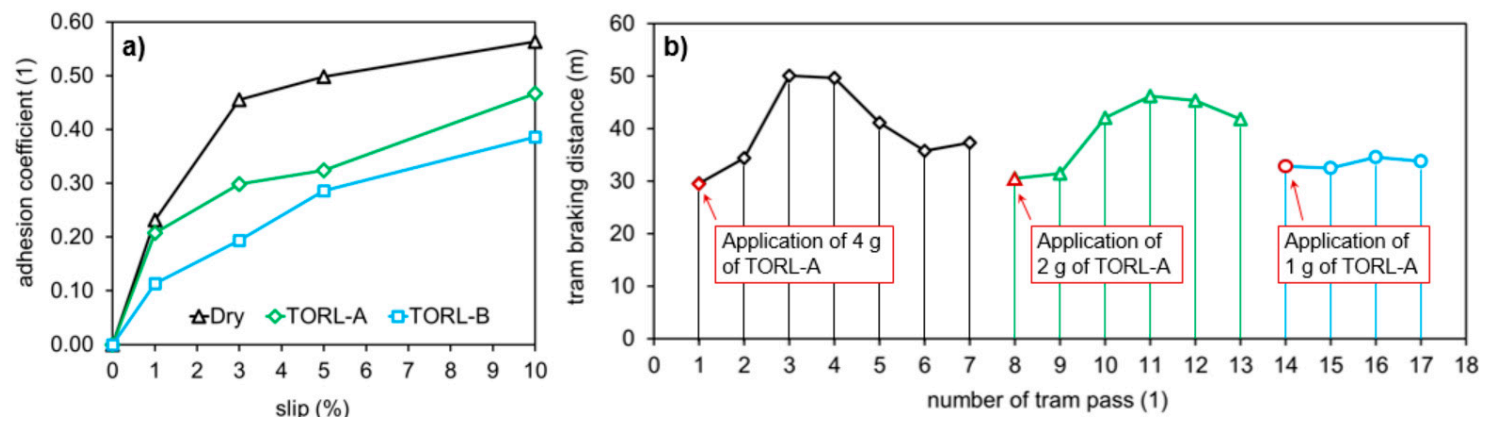

Figure 1. Adhesion curves for dry and lubricated conditions (a) and the effect of TOR lubricant quantity on tram braking distance $(\mathbf{b})$.

\section{Conclusions and Discussion}

This study showed that TOR lubricants are able to provide the intermediate adhesion level and reduce wear and surface damage. Moreover, positive friction characteristic was observed for both tested TOR lubricants. However, this positive trend of adhesion curve was also found for dry conditions where the negative trend of adhesion curve is expected. Therefore, it seems to be necessary to approve this ability by another experimental method.

Field experiments showed that TOR lubricants can cause unacceptable long braking distance if the contact is overdosed by TOR lubricant. Therefore, it was suggested that the application of TOR lubricant using off-board system with application strip is not suitable method and another way of application should be considered in the future research. Moreover, another way of application can ensure better spreading of TOR lubricant along the track; thus, more significant reduction of noise can be expected.

Acknowledgments: The authors are sincerely grateful to European Commission for the financial sponsorship of the H2020-MSCA-RISE Project No. 691135 “RISEN: Rail Infrastructure Systems Engineering Network," which enables a global research network that tackles the grand challenge in railway infrastructure resilience and advanced.

\section{References}

1. Galas, R.; Kvarda, D.; Omasta, M.; Krupka, I.; Hartl, M. Laboratory investigation of ability of oil-based friction modifiers to control adhesion at wheel-rail interface. Wear 2016, 368-369, 230-238.

2. Galas, R.; Omasta, M.; Klapka, M.; Kaewunruen, S.; Krupka, I.; Hartl, M. Case study: The influence of oilbased friction modifier quantity on tram braking distance and noise. Trib. Ind. 2017, 39, 198-206.

(C) 2018 by the authors. Licensee MDPI, Basel, Switzerland. This article is an open access article distributed under the terms and conditions of the Creative Commons Attribution (CC BY) license (http://creativecommons.org/licenses/by/4.0/). 